\title{
Impact Response of Hammerhead Pier Fibrous Concrete Beams Designed with Topology Optimization
}

\author{
Meivazhisalai Parasuraman Salaimanimagudam¹, Covaty Ravi Suribabu, \\ Gunasekaran Murali ${ }^{1 *}$,Sallal R. Abid ${ }^{2}$

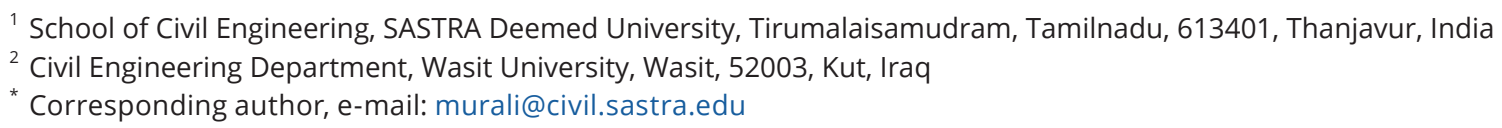

Received: 14 June 2020, Accepted: 21 July 2020, Published online: 18 September 2020

\begin{abstract}
Reducing the weight of concrete beams is a primary (beyond strength and durability) concern of engineers. Therefore, this research was directed to investigate the impact response of hammerhead pier concrete beams designed with density-based method topology optimization. The finite element topology optimization was conducted using Autodesk fusion 360 considering three different mesh sizes of $7 \mathrm{~mm}, 10 \mathrm{~mm}$, and adaptive meshing. Three optimized hammerhead beam configurations; HB1, HB2, and HB3, respectively, with volume reductions greater than $50 \%$. In the experimental part of this research, nine beams were cast with identical size and configuration to the optimized beams. Three beams, identical to the optimized beams, were tested under static bending for verification purposes. In comparison, six more beams, as in the preceding three beams but without and with hooked end steel fibers, were tested under repeated impact load. The test results revealed that the highest flexural capacity and impact resistance at crack initiation and failure were recorded for the adaptive mesh beams (HB3 and HB3SF). The failure impact energy and ductility ratio of the beam HB3SF was higher than the beams HB1SF and HB2SF by more than $270 \%$. The results showed that the inclusion of steel fiber duplicated the optimized beam's impact strength and ductility several times. The failure impact resistance of fibrous beams was higher than their corresponding plain beams by approximately 2300 to $4460 \%$, while their impact ductility ratios were higher by 6.0 to 18.1 times.
\end{abstract}

Keywords

topology optimization, hammerhead pier beam, repeated impact, steel fibers, finite element

\section{Introduction}

Weight reduction of concrete structural members within the limits of stresses, deflection, and stiffness, has come to be the primary aim of optimization [1]. The topological optimization of structural members acts as a vital tool to reduce the volume of the material that creates ground-breaking layouts and a higher degree of structural integrity without compromising performance [2]. Topological optimization is gaining importance among design engineers as clients warrant cost reduction. Simultaneously, the structure is made up of the same sub-components, for instance, the beam required for the hammerhead column for supporting long bridge deck slabs. The lightweight superstructure is the most effective way to counteract seismic forces and topological optimization-based designs are increasingly preferred in such circumstances. When structural members are being optimized based on topological configuration, it not only provides weight reduction but also expands the solution space to locate the optimal solution [3]. Recently, Liew et al. [4] conceived and built a floor slab with pure compression, obviating reinforcement (except, perhaps for temperature stresses). The emerging concept of frameworks, integrated with newer and innovative construction methods leads to optimal design for every phase of the structural element distinctly.

Numerous investigators have brought forward the algorithms for topology optimization for reinforced concrete design in recent years. The majority have geared towards using Strut-and-Tie models for designing placing reinforcements at optimal locations and in the most effective directions. The opening line of a suggested course of action assumes concrete as anisotropic and elastic material $[5,6]$, or density-based methods [7, 8]. Strut-and-Tie Model's topology optimization with the different modules in the two reinforced concrete phases was proposed 
later [9-11]. Ali and White [12] proposed nonlinear Strutand-Tie Models using the elastoplastic truss algorithm. The continuum outline for the design of the conceptual reinforcement phase in both reinforced concrete phases has elastoplastic performances and Bogomolny and Amir [13] proposed it. Shaw et al. [14] developed a new technique for column design for orthogonal structures. For a design of rectilinear floors in the beam-slab layout, a genetic algorithm-based technique was proposed by Nimtawat and Nanakorn [15, 16]. Briseghella et al. [17] emphasized that the tension zone inevitable stresses could be taken care of by material-removing from the shell regions in which bending occurs. This creates voids in concrete that satisfy conditions of topology optimization.

The design layout of topology optimization of the distribution of fibers and its orientation in fibrous reinforced concrete has been proposed by many researchers [18-20]. Further comprising the design of the reinforcing phase alone, algorithms based topology optimization has been offered for the design of both phases to enhance the destruction strength of lightweight elements [21]. Recently, an algorithmic topology optimization for the design of lightweight post-tensioned reinforced concrete was suggested by Amir and Shakour [22]. Søndergaard and Dombernowsky [23] investigated a reinforced concrete frame designed by the assumption of isotropic behavior of the material in an initial phase of design. Its results were post-processed by the addition of reinforcement to counter tensile forces in the frame. Of late, Oviedo et al. [24] examined experimentally the topology optimized Strut-and-Tie Models for a dapped beam; in these designs. However, substantial post-processing was carried out to the continuum topology-optimized outcomes. Enhanced ultimate strength and improved crack augmentation control were detected. The contemporary dearth of experimental corroborations poses a major stumbling block for further improvement and practice of topology optimization skeletons for reinforced concrete design. As reinforced concrete is an intricate composite, this line of work emphasizes precisely designing for the concrete phase, an indispensable stage in truly allowing the freeform design of both reinforced concrete phases.

On the contrary, concrete structures during their service life might conceivably be exposed to the threat of impact loads from diverse sources [25]. In practical terms, several impact situations in engineering can be considered, for instance, ship/barge bumping into bridge pier or offshore structures, industrial flooring, vehicle strikes on transportation structure, barriers, structures exposed to pipe whipping, sudden falling rocks, etc. [26]. The frequency and possibility of these types of impacts are considerably higher. Henceforth, the evaluation of the performance of the concrete structure under impact load is of considerable importance for safe and economical design [27]. Plain concrete has exposed poor tensile strength, the lesser extent of ductility, and collision energy absorption, limiting the concrete ability to withstand impact loading [28]. The addition of fiber to concrete has exhibited high ductility [29] and toughness [30]. Mainly, the role of fibers in the concrete is a too restricting crack extension and imparting higher post crack strength, but avoiding provoking brittle failure [31].

In a nutshell from the above literature review, it is noted that the impact response of a different type of concrete, fibers, and structural elements have been evaluated and discussed extensively by researchers [32-35]. Likewise, a numerical response of topology optimization of plain concrete structural elements was explored to a sufficient degree [7, 11, 36, 37]. Unfortunately, results for impact response of structural elements designed with topology optimizations are not readily available. In this context, the static and impact response of topology optimized hammerhead pier beams were examined using Autodesk fusion. The experimental performance of non-fibrous and fibrous concrete beams was compared and discussed.

\section{Significance and layout of the research}

Despite the wide availability of results from the study of a topology optimized structural elements and impact response of fibrous concrete, research on topology optimized structural element and its performance outcome explicitly under impact loading is scarce. There is a dearth of information regarding the impact response of hammerhead pier concrete beams. This is the specific research gap identified from the literature review and the research reported herein is an effort towards filling this gap. To achieve this goal, a procedure that includes subsequent steps of numerical and experimental programs was conducted. The layout of the adopted procedure is summarized in Fig. 1 and is as follows:

(1) In this first step, topology optimization was conducted using the Finite Element (FE) package Autodesk Fusion 360 to optimize the shape of hammerhead beams based on its actual loading configuration in bridges. The optimization was conducted using three different FE mesh discretization sizes which resulted in three optimized beams HB1, HB2 and HB3. 


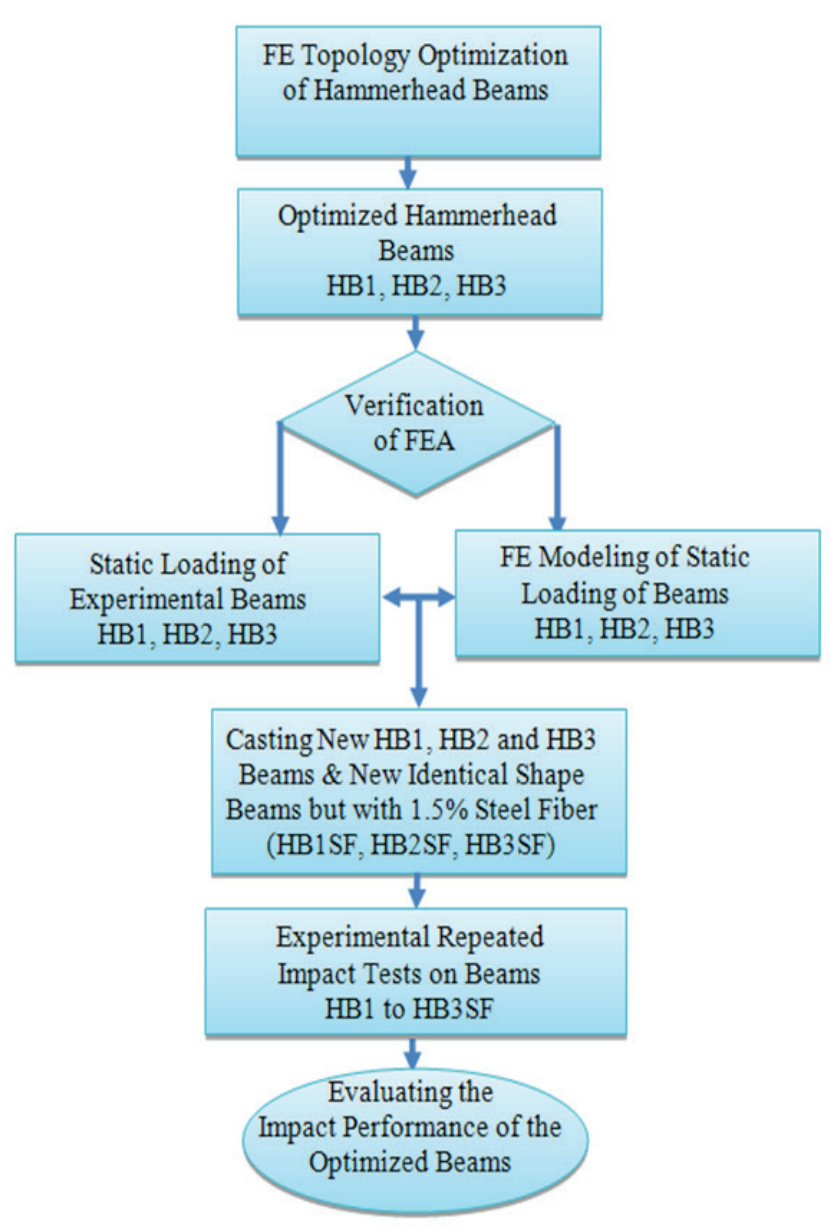

Fig. 1 Layout of the optimization, FE, and experimental studies conducted in this research

(2) Based on the available testing machine dimensions, experimental beams having the same optimized configurations and dimensions of beams HB1, HB2, and HB3 are cast and tested in static bending tests. In parallel, the optimized beams FE models of HB1, HB2, and HB3 were also tested in static bending under the same experimental testing circumstances. This step was conducted to verify the FE analysis used topology optimized the beams HB1, $\mathrm{HB} 2$, and HB3.

(3) In the next step, the experimental work was extended to cast new six beams to conduct the repeated impact test to investigate the impact response of the optimized beams. Three beams are identical to the preceding beams HB1, HB2, and HB3, where both configuration and materials are the same, while three more beams (HB1SF, HB2SF, and HB3SF) having the same configurations of HB1, HB2, and $\mathrm{HB} 3$, respectively, were cast with the addition of $1.5 \%$ of steel fiber. These beams were directed to evaluate the effect of steel fiber on the optimized hammerhead beams impact performance.

\section{Topology optimization and FE analysis of hammerhead pier beam \\ 3.1 Topology optimization}

Numerous suggestions were made based on methods in topology optimization (see an outline in e.g. [38]). In most of the methods, a design area with constraints and loads applied as defined by the design engineer. The problematic design is articulated as a formalized problem in optimization and most meticulously cracked with the help of mathematical programming. The current research uses an approach of solid isotropic material penalization (SIMP). The SIMP approach is infrequently defined as a density method that operates with fixed finite element discretization. In the SIMP approach, each finite element is connected with a density function $X_{e}$. The design target is to determine a 0 -1 element densities distribution that optimizes a defined goal though satisfying the equilibrium of structure and number of constraints. It also allows the use of gradient-based optimizers, the constraints of $0-1$ binary is made easy and densities at intermediate levels $\left(0 \leq X_{e} \leq 1\right)$ are permitted as the design evolved. Conversely, the densities at the intermediate levels are pruned towards reducing the use of the material inefficiently. This results in the optimizer being directed from an initiatory smeared assumption with a view towards a separate structural key.

In this research, the $3 \mathrm{D}$ hammerhead pier beam is used in the design field, as illustrated in Fig. 2. The optimization analysis of the hammerhead pier beams was conducted using the Autodesk Fusion 360 program. Because of the loading and size limitations of the available laboratory testing device, the domain length, depth and thickness were defined as $L=910 \mathrm{~mm}, H=230 \mathrm{~mm}$, and $T=76 \mathrm{~mm}$, respectively. The load $\mathrm{P}=2.2 \mathrm{kN}$ applied at the top surface of the beam at four different points and constraints are positioned at the bottom center of the beam with the ratio of $L / 6$. In the Autodesk Fusion 360 FE optimization analysis, the beams were discretized with three different mesh sizes (i) $5 \%$ of adaptive meshing (can be controlled from

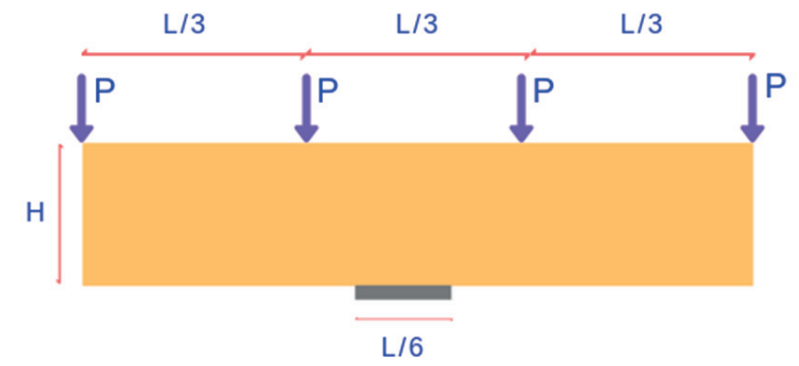

Fig. 2 Design field with constraints and the load applied for all design cases in this research 
1 to $10 \%$ ), (ii) $7 \mathrm{~mm}$, and (iii) $10 \mathrm{~mm}$. The concrete hammerhead pier beam is presumed to behave isotropic and linearly elastic in all design situations. For the assumption of isotropic to be some extent strong for the pilot research, a scale prerequisite with the smallest length on the topological structures is imposed. Table 1 demonstrates the assigned material property used in this research.

The topology optimization frameworks based on stress have been proposed by many researchers [39-47], and a thorough examination is beyond the scope of this research. Frequently, the aim of stress-limitation methods is considered as to reducing the volume to guarantee that the applied design load is less than the permissible stress limits. More often, von Missesstresses are imposed on the permissible stress limits. Nevertheless, von Missesstress can be imposed only for the tension and compression strength limits. Consequently, a condition of DruckerPrager stress [48] is herewith chosen since it permits for diverse levels of strength. The principal stress plane $\left(\sigma_{1}, \sigma_{2}\right)$ yield criteria for von Misses and the Drucker-Prager stress are compared with a ratio of compression to tension $s=$ 2.5 is illustrated in Fig. 3. It is noticed in the graph region that the criterion of Drucker-Prager permits lower stress in tension than in compression. Though, the graph also divulges that the criterion of Drucker-Prager permits high biaxial compressive stress states. For $s=2.5$ values for the design of concrete is characteristically about five times more than that illustrated in Fig. 3,which is around ten times. This propensity is pronounced further and could trigger insufficiency to capture compression failure.

The topology optimization framework is more advantageous than the traditional approach of FEA. It gives the response to the optimization engine to provide optimal

Table 1 Property of material used in this research

\begin{tabular}{|c|c|c|}
\hline Description & $\begin{array}{l}\text { Non-fibrous } \\
\text { concrete }\end{array}$ & Fibrous concrete \\
\hline Density & $2.407 \mathrm{E}-06 \mathrm{~kg} / \mathrm{m}$ & $2.547 \mathrm{E}-06 \mathrm{~kg} / \mathrm{m}$ \\
\hline Young's modulus & $31004 \mathrm{MPa}$ & $36500 \mathrm{MPa}$ \\
\hline Poisson's ratio & 0.2 & 0.2 \\
\hline $\begin{array}{l}\text { Concrete Compressive } \\
\text { Strength }\end{array}$ & $40 \mathrm{MPa}$ & $55 \mathrm{MPa}$ \\
\hline Yield strength & $4 \mathrm{MPa}$ & $6 \mathrm{MPa}$ \\
\hline $\begin{array}{l}\text { Ultimate Tensile } \\
\text { Strength }\end{array}$ & $4 \mathrm{MPa}$ & $6.5 \mathrm{MPa}$ \\
\hline Thermal Conductivity & $0.0016 \mathrm{~W} /(\mathrm{mm} \mathrm{C})$ & $0.0016 \mathrm{~W} /(\mathrm{mm} \mathrm{C})$ \\
\hline $\begin{array}{l}\text { Thermal Expansion } \\
\text { Coefficient }\end{array}$ & $1 \mathrm{E}-05 / \mathrm{C}$ & $1 \mathrm{E}-05 / \mathrm{C}$ \\
\hline Specific Heat & $800 \mathrm{~J} /(\mathrm{kg} \mathrm{C})$ & $800 \mathrm{~J} /(\mathrm{kg} \mathrm{C})$ \\
\hline
\end{tabular}

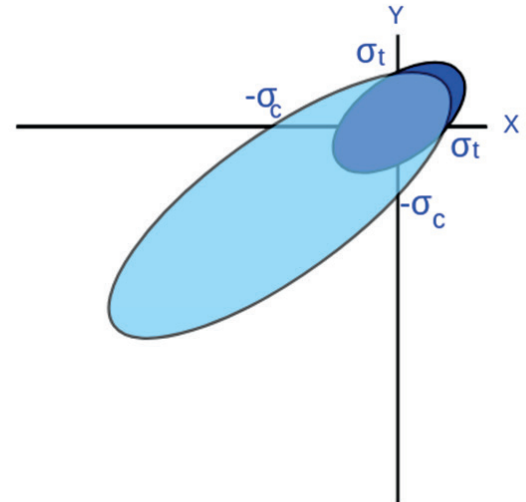

Von Mises
Drucker-Prager

Fig. 3 The principal stress axis for the yield criteria of von Misses and the Drucker-Pragerwith $s=2.5$

topology components according to the defined design variables and constraints. Standard pre-processing of the Fusion 360 bulk data file includes specific optimization objectives, constraints, and parameters. Additional pre-processing of optimization specific data such as adjacency, distances, manufacturing constraint dependency, and initial volume fraction are considered in the analysis. In the design process of topological optimization, iteration starts with calculating stiffness followed by mass matrices, and all subsequent changes are scaled. The optimization engine simply decides new design variables (scaled stiffness and mass) and determines until the stopping criteria are satisfied. Initially, the first iteration calculates stiffness and mass matrices and all subsequent calculations are scaled. Two optimization engines were used in this analysis, which is the Optimality Criteria Method (OCM) [49, 50] and the Moving Method Asymptotes (MMA) [21, 51]. Fig. 4 illustrates the implementation procedure of the proposed frame. Fig. 5 illustrates the hammerhead pier beam shapes that were obtained from the topology optimization for the three adopted mesh sizes. The volume reductions of the optimized beams HB1, HB2, and HB3 were 55.16, 53.19, and $50.16 \%$, respectively.

\subsection{FE analysis of the optimized beams}

After conducting the optimization analysis, experimental models (discussed in the following section), and numerical models in the numerical analysis, load and deformation behavior of hammerhead pier beams were studied under static load. The outcomes achieved from the numerical simulation were related to those from the experimental outcome. 


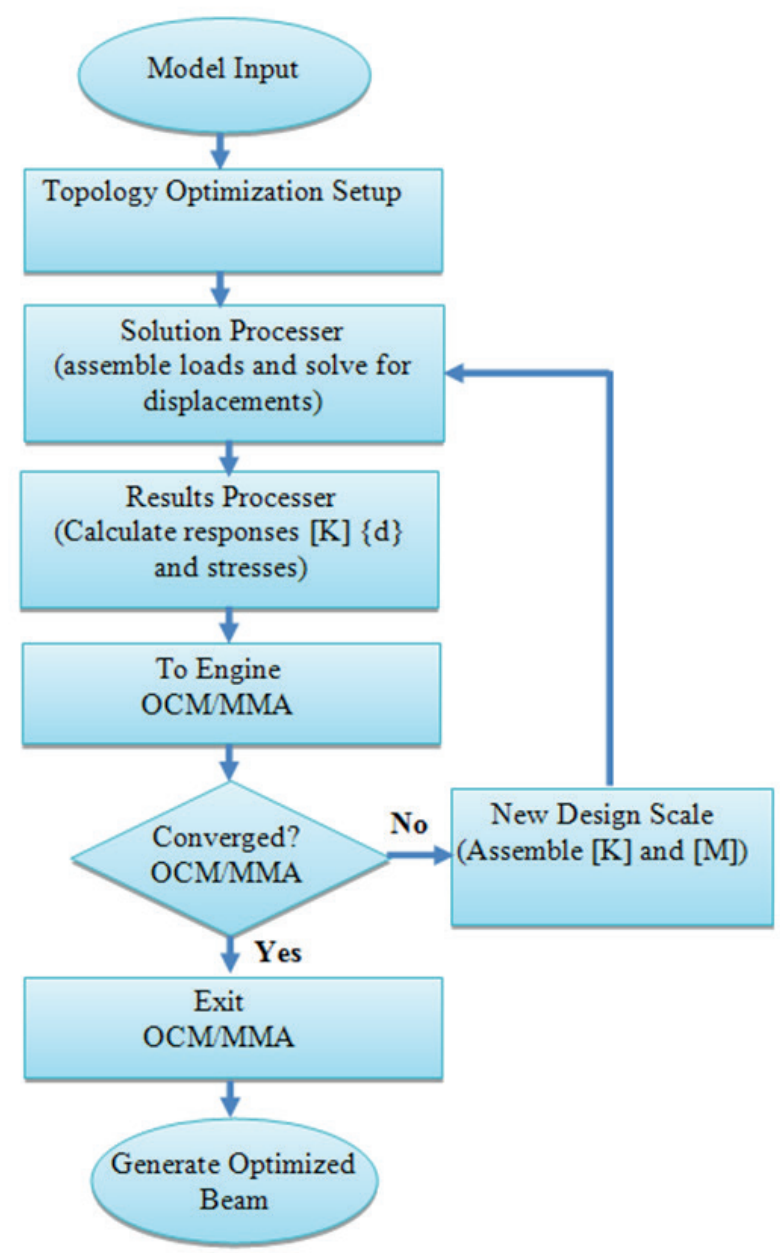

Fig. 4 Framework of the topology optimization

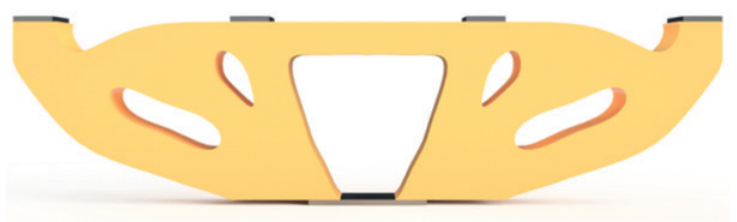

(a) HB1

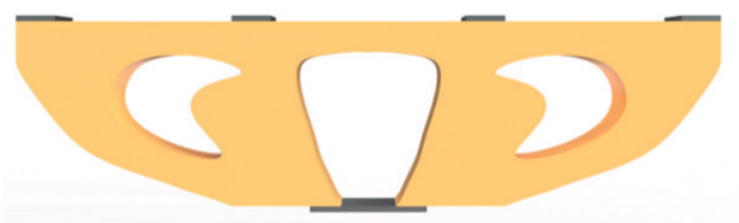

(a) HB2

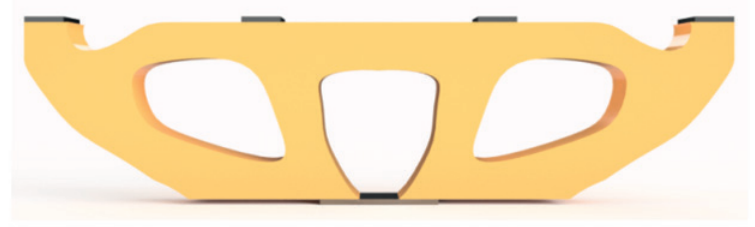

(c) HB3
The static responses of the optimized hammerhead pier beams were studied using the Autodesk Fusion 360 program, which has been extensively evidenced to be consistent in the computation of structural behavior and failure under the static loading. Exploiting the beam symmetrically, it is analyzed by varying three mesh sizes, with $7 \mathrm{~mm}, 10 \mathrm{~mm}$, and adaptive mesh. All beams, plates for support, and loading were modeled using the designed experimental (detailed in the next section) dimensions for verification purposes. The material properties, including the density, modulus of elasticity, compressive strength, and tensile strength, were well defined based on the experimental measurements to assure more accurate modeling. In the present section, the schemes and properties of the assigned material, constraints used for the hammerhead pier beam are described in Table 2. Fig. 6 illustrates the static bending test modeling of the optimized beams in Autodesk Fusion 360 software based on the three mesh sizes. The optimized beams have taken to event simulation in Autodesk Fusion 360 to define the materials and apply the constraints. All base plates, the assigned constraints, are fixed in all three axes to restrict their movements.

Table 2 Summary of the parameters used in the FE analysis

\begin{tabular}{|c|c|c|c|}
\hline Description & HB1 & HB2 & HB3 \\
\hline $\begin{array}{l}\text { Scale Mesh Size } \\
\text { Per Part }\end{array}$ & No & No & Yes \\
\hline $\begin{array}{l}\text { Average Element } \\
\text { Size }\end{array}$ & $\begin{array}{c}7 \mathrm{~mm} \\
\text { (absolute size) }\end{array}$ & $\begin{array}{c}10 \mathrm{~mm} \\
\text { (absolute size) }\end{array}$ & $\begin{array}{l}1 \% \text { (model- } \\
\text { based size) }\end{array}$ \\
\hline Element Order & Parabolic & Parabolic & Parabolic \\
\hline $\begin{array}{l}\text { Create Curved } \\
\text { Mesh Elements }\end{array}$ & Yes & Yes & Yes \\
\hline $\begin{array}{l}\text { Max. Turn Angle } \\
\text { on Curves (Deg.) }\end{array}$ & 60 & 60 & 60 \\
\hline $\begin{array}{l}\text { Max. Adjacent } \\
\text { Mesh Size Ratio }\end{array}$ & 1.5 & 1.5 & 1.5 \\
\hline $\begin{array}{l}\text { Minimum } \\
\text { Element Size ( } \% \\
\text { of average size) }\end{array}$ & 10 & 10 & 10 \\
\hline $\begin{array}{l}\text { Max. Aspect } \\
\text { Ratio }\end{array}$ & 20 & 20 & 20 \\
\hline $\begin{array}{l}\text { Number of } \\
\text { Refinement Steps }\end{array}$ & 6 & 6 & 6 \\
\hline $\begin{array}{l}\text { Results } \\
\text { Convergence } \\
\text { Tolerance (\%) }\end{array}$ & 5 & 5 & 5 \\
\hline $\begin{array}{l}\text { Portion of } \\
\text { Elements to } \\
\text { Refine (\%) }\end{array}$ & 40 & 40 & 40 \\
\hline Number of nodes & 435,322 & 163,323 & 202,784 \\
\hline $\begin{array}{l}\text { Number of } \\
\text { elements }\end{array}$ & 304,884 & 111,672 & 139,501 \\
\hline
\end{tabular}

Fig. 5 Hammerhead pier beams from the topology optimization 


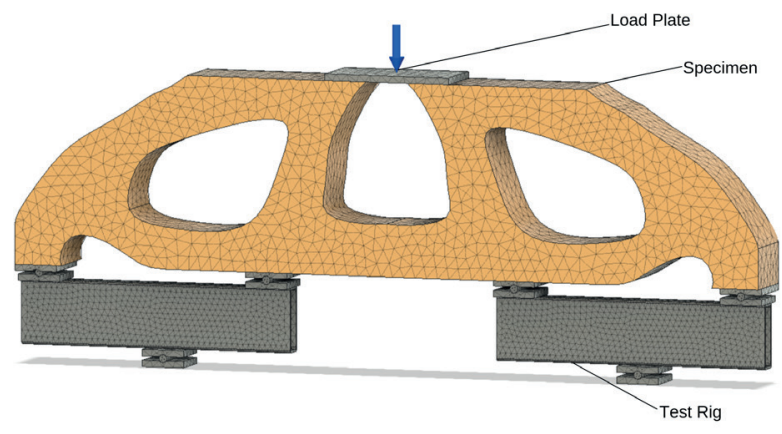

Fig. 6 Static bending test setup and meshing in Autodesk fusion 360

\section{Experimental work}

\subsection{Experimental program}

As detailed in Section 2, the experimental work of this research consists of two parts. In the first part, three hammerhead pier beams that are identical to the optimized beams HB1, HB2, and HB3 were cast. All beams were tested under static bending to evaluate the accuracy of the conducted FE analysis. In the second part, six beams were cast to conduct repeated impact tests on the optimized hammerhead beams. Among these, three were identical to the experimental beams HB1, HB2, and HB3. The other three beams were identical in geometry to the beams HB1, $\mathrm{HB} 2$, and HB3, yet the material used was different. The second three beams were an extended part to evaluate the effect of steel fibers on the impact response of the optimized hammerhead beams. Therefore, the same concrete mixture was used, but with the addition of $1.5 \%$ steel fiber. These beams were identified as HB1SF, HB2SF, and HB3SF, where the letters "SF" refer to the used steel fiber. In total, nine beams were cast in this study and tested under static bending tests and repeated impact test. The details of nine beams are given in Table 3 .

\subsection{Materials and mixtures}

A single concrete mixture (excluding the use of fiber) was used for all of the cast nine beams and control test specimens. The dray mixture composed of $450 \mathrm{~kg} / \mathrm{m}^{3}$ cement, $645 \mathrm{~kg} / \mathrm{m}^{3}$ sand, and $10180 \mathrm{~kg} / \mathrm{m}^{3}$ gravel, while the water-cement ratio of the mixture was 0.35 and the superplasticizer content was $2.2 \%$ of cement weight. Ordinary Portland cement of 53 grade was used in conformity with IS: 122692013 [52], supplied by Ramco Cement, while natural river sand was used as fine aggregate with 3.2 and 3.14 fineness modulus and specific gravity respectively, conforming to IS383-2016 [53]. Well, graded coarse aggregates used were crushed granite gravel of size around $12.5 \mathrm{~mm}$ purchased
Table 3 Details of the nine experimental hammerhead pier beams

\begin{tabular}{|c|c|c|c|}
\hline $\begin{array}{l}\text { Beam } \\
\text { ID }\end{array}$ & $\begin{array}{c}\text { Number of Beams } \\
\text { and Tests }\end{array}$ & Variables Investigated & $\begin{array}{l}\text { Fiber } \\
(\%)\end{array}$ \\
\hline HB1 & $\begin{array}{l}2 \text { (1 Static bending + } \\
1 \text { Repeated impact) }\end{array}$ & Optimized Configuration & 0 \\
\hline HB2 & $\begin{array}{l}2 \text { (1 Static bending + } \\
1 \text { Repeated impact) }\end{array}$ & Optimized Configuration & 0 \\
\hline HB3 & $\begin{array}{l}2 \text { (1 Static bending + } \\
1 \text { Repeated impact) }\end{array}$ & Optimized Configuration & 0 \\
\hline HB1SF & 1 (Repeated impact) & $\begin{array}{c}\text { Optimized Configuration } \\
\text { \& Steel Fiber }\end{array}$ & 1.5 \\
\hline $\mathrm{HB} 2 \mathrm{SF}$ & 1 (Repeated impact) & $\begin{array}{c}\text { Optimized Configuration } \\
\text { \& Steel Fiber }\end{array}$ & 1.5 \\
\hline HB3SF & 1 (Repeated impact) & $\begin{array}{c}\text { Optimized Configuration } \\
\text { \& Steel Fiber }\end{array}$ & 1.5 \\
\hline
\end{tabular}

locally. A superplasticizer with the commercial name of FosrocConplast SP430 was used to produce the workable fibrous concrete with a maintained slump value of $40 \mathrm{~mm}$. Hooked end steel fibers with a diameter of 0.5 and a length of $30 \mathrm{~mm}$ were used in this study. The tensile strength of the used fibers was $1200 \mathrm{MPa}$.

During the start-up phase, dry particles (cement and fine aggregate) were poured into a mixer machine and mixed for 5 minutes at $50 \mathrm{rpm}$. Later, coarse aggregates and fibers were added and mixed for a further 5 minutes. Then superplasticizer (SP) was dissolved first in a small portion of water meant for concrete mixed until fibers were well-dispersed in the matrix without the effect of fiber balling.

\subsection{Configuration and instrumentation of the static bending test}

All pilot trials of the static bending test were carried out using the deflection control-self-balancing loading frame. A test rig of steel tubes with square cross-section offered the deformations to the four points loading by stringer the right balance of a steel tube at its focal point on steel rods. In this experimental design, the support conditions were provided by introducing the rectangular steel plate, which was bonded at the outermost concrete surface using high strength epoxy. To observe deformations at the four loading points, four Linear Variable Differential Transformers (LVDT) was employed. The compliance beam with the LVDT test fixture is illustrated in Fig. 7. Though the design in this research was limited to beams inelastic range, all beams were loaded till failure to observe nonlinear behavior. 


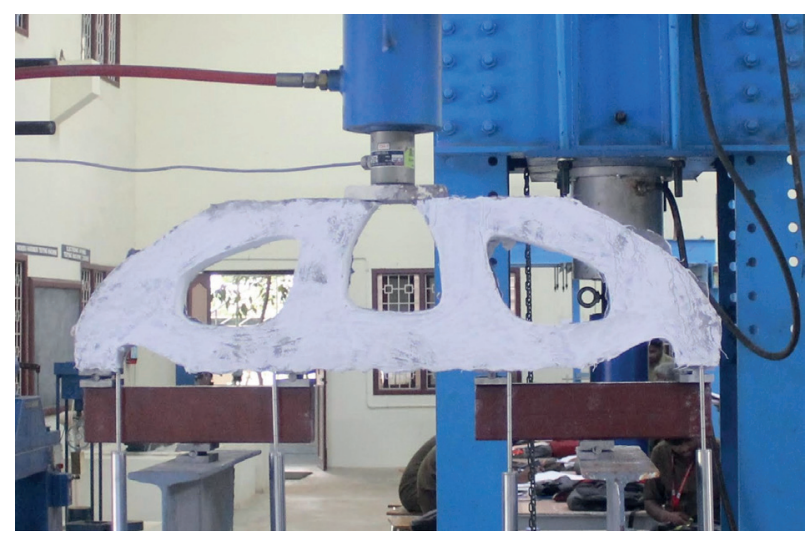

Fig. 7 Test setup of static bending of the optimized beams

\subsection{Configuration and instrumentation of the repeated impact test}

The falling mass test was conducted conforming to ACI committee 544 [54]. Two $4.45 \mathrm{~kg}$ steel balls were dropped freely from $457 \mathrm{~mm}$ height on to the upmost surface of one-third of the span from each side as illustrated in Fig. 8. For a period of a multiplicity of falling mass collision test, impact responses of hammerhead pier beam were observed, the requisite number of replicated impact till crack initiation was defined by $(\mathrm{O} 1)$ whereas the requisite number of replicated impact till ultimate crack was denoted by $(\mathrm{O} 2)$.

Crack growth evolving from the bottom surface to the top surface of the beam signifies failure. Crack initiation and failure were observed visually. Collision energy at $\mathrm{O} 1$ and $\mathrm{O} 2$ were determined as follows.

Collision energy $(U)=N \times m \times g \times H$

Where $N$ is the number of replicated impacts, $\mathrm{m}$ is the mass of dropping steel ball $(4.45 \mathrm{~kg}), \mathrm{g}$ is the acceleration due to gravity $\left(9.81 \mathrm{~m} / \mathrm{s}^{2}\right)$, and $\mathrm{H}$ denotes the height of free fall $(457 \mathrm{~mm})$.

\section{Experimental and $\mathrm{FE}$ results of the static bending test} Since all topology optimized beams were fabricated and tested until failure, the possibility exists to address the consequence of design cases in the nonlinear range [55]. Though, it is worth recalling that the design considered in this study was based on linear performance. Table 4

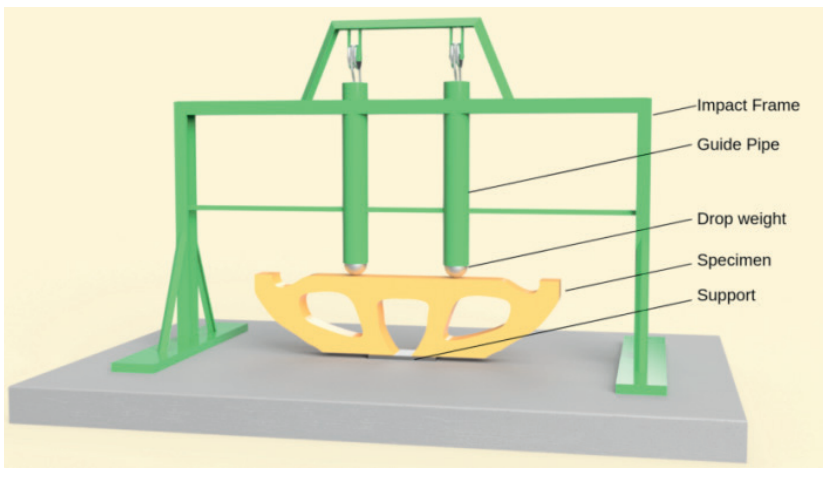

Fig. 8 Test setup of the repeated impact test of the optimized beams

compares the failure loads and deflections of the experimental and FE beams HB1, HB2, and HB3, Fig. 9 illustrates the experimental and FE load-deflection curves of these beams. It is listed in Table 4 and shown in Fig. 9 that the experimental failure load and the deflection values of the HB1 beam were $14.8 \mathrm{kN}$ and $0.2 \mathrm{~mm}$, respectively. The adopted mesh size for this design case was $7 \mathrm{~mm}$ with an as-built volume of material was $55.16 \%$. Likewise, the failure load and deflection of the HB2 beam were $6 \mathrm{kN}$ and $0.14 \mathrm{~mm}$ respectively, with the as-built volume of material was $53.19 \%$ and $10 \mathrm{~mm}$ mesh size. Comparing the beams $\mathrm{HB} 1$ and HB2, it is obvious that an intrinsic increment in the failure load of the HB1 beam of $146.6 \%$ over the HB2 beam was recorded. For the domain, applied loads and constraints used in this work, the HB3 beam attained the maximum value of the applied load with the as-built volume of material was $50.16 \%$. The failure load of the HB3 beam was $81 \%$ higher than that of $\mathrm{HB} 2$ and $346.6 \%$ higher than that of the HB1 beam. On the other hand, FE failure loads and deflections of the beams HB1, HB2, and HB3 beams were $16 \mathrm{kN}, 8 \mathrm{kN}$, and $28 \mathrm{kN}$, respectively, while their corresponding deflections were as shown in Table 4. Considering the deflection records of the experimental and FE beams, Table 4 shows that differences or errors were between 0.008 and $0.0043 \mathrm{~mm}$ for the three beams with percentage errors in the range of 6.3 to $11.9 \%$. Similarly, the percentage of errors in failure loads between the experimental and FE beams were $8.1 \%$ for beam HB1 and $4.3 \%$ for beam HB3, while due to the low failure load value of beam

Table 4 Comparison of experimental and FE static bending tests of optimized beams

\begin{tabular}{|c|c|c|c|c|c|c|}
\hline \multirow{2}{*}{ Beams ID } & \multicolumn{3}{|c|}{ Load (kN) } & \multicolumn{3}{|c|}{ Deflection (mm) } \\
\hline & Experimental & $\mathrm{FE}$ & $\%$ Error & Experimental & $\mathrm{FE}$ & $\%$ Error \\
\hline HB1 & 14.8 & 16 & 8.1 & 0.2 & 0.214 & 6.3 \\
\hline HB2 & 6 & 8 & 33.3 & 0.14 & 0.132 & 6.4 \\
\hline HB3 & 26.8 & 28 & 4.3 & 0.325 & 0.368 & 11.9 \\
\hline
\end{tabular}



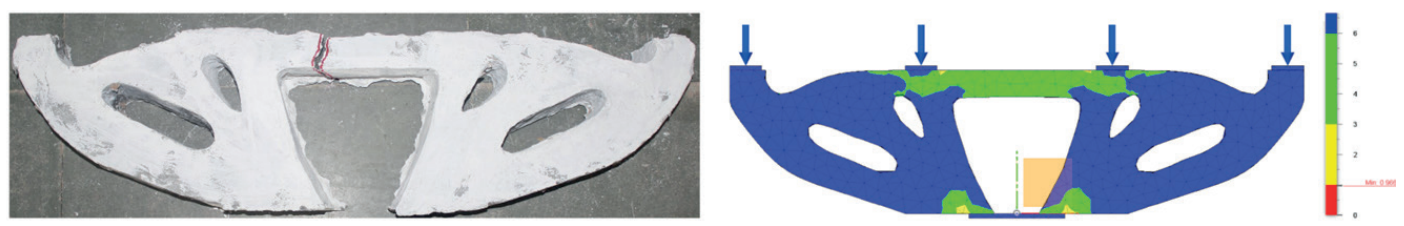

(a) $\mathrm{HB1}$
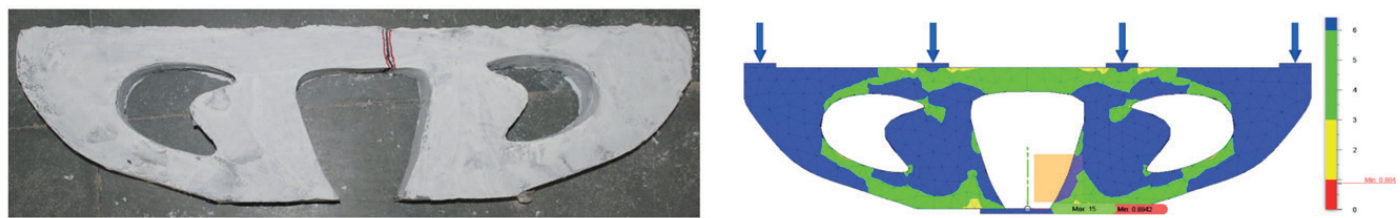

(b)HB2
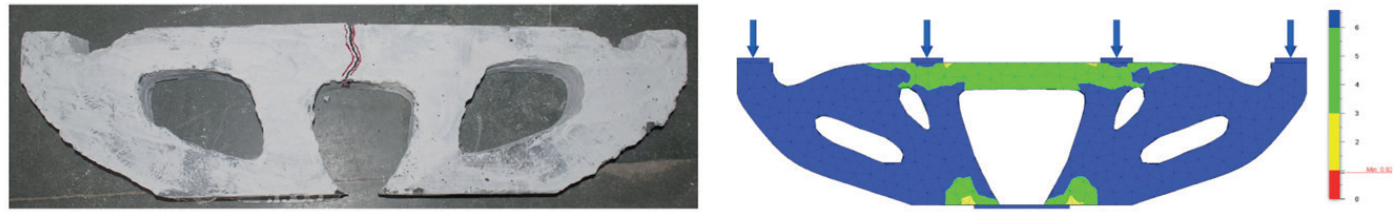

(c)HB3

Fig. 9 Experimental and FE cracking pattern of hammerhead pier beam under static load

$\mathrm{HB} 2$, the difference was $2 \mathrm{kN}$, which is $33 \%$ of the experimental load. Excluding the failure load of HB2, it is evident that good agreement was attained between the experimental and FE failure loads and the optimized beams deflections.

The different load and deflection values of the three beams reflect their different strength and behaviors under loads, which shows that mesh size significantly affects the finite element topology optimization results. The results also show that the adaptive mesh is more effective in the topology optimization of hammerhead beams than selective mesh sizes. This results in optimized sections with a relatively similar reduction in the cross-sectional area but with noticeably higher strength.

Brittle behavior was noticed in the tested beams, where they were breaking down into two fragments, as illustrated in Fig. 9. The cracking pattern from the numerical simulation was presented in terms of the safety factor. The failure under the static load was acknowledged based on the value of the factor of safety which is close to 1 . It can be noticed that the cracking patterns of FEhammerhead beams well agree with the failure patterns of the same experimental hammerhead pier beams, which supports the accuracy of the introduced FE models.

\section{Experimental results of repeated impact test 6.1 Impact results of hammerhead pier beams}

As addressed in the previous sections, the main goal of this research is to investigate the impact response of the optimized hammerhead beams under repeated impact test.
The discussion in this section focuses on the effect of optimized shape and the effect of steel fiber. The former is investigated by the comparison among the beams HB1, HB2, and HB3 and the beams HB1SF, HB2SF, and

HB3SF. The effect of steel fiber is investigated by each plain beam with its corresponding fibrous beam (HB1 with HB1SF, HB2 with HB2SF, and HB3 with HB3SF). The discussion of this section is presented in terms of the retained numbers of impact blows at cracking $(\mathrm{O} 1)$ and failure $(\mathrm{O} 2)$ stages and their corresponding impact energies $\mathrm{U} 1$ and $\mathrm{U} 2$.

It is obvious in Fig. 10(a) that the plain beams (without fiber) retained noticeably lower cracking numbers of impact blows (O1) than their corresponding fibrous beams. The retained $\mathrm{O} 1$ values of beams HB1, HB2, and HB3 were only 1,1 , and 2 , while the retained $\mathrm{O} 1$ values of the corresponding $\mathrm{HB} 1 \mathrm{SF}, \mathrm{HB} 2 \mathrm{SF}$, and $\mathrm{HB} 3 \mathrm{SF}$ were 7, 6, and 7, respectively. This means that plain beams were very brittle under impact loads, where only one or two impacts were enough to initiate cracking. On the other hand, the inclusion of steel fibers postponed crack initiation to not less than six impact blows, reflecting the activity of fibers to increase the energy absorption of the tested specimens even before crack initiation [56]. Fig. 10(b) shows that fibrous beams were much superior to plain ones, where the beams HB1, HB2, and HB3 were failed after few $\mathrm{O} 2$ impacts of 2, 2, and 3, respectively, while the fibrous beams HB1SF, HB2SF, and HB3SF retained much higher numbers of 49, 46 and 134, respectively. Using steel fiber could dramatically increase 


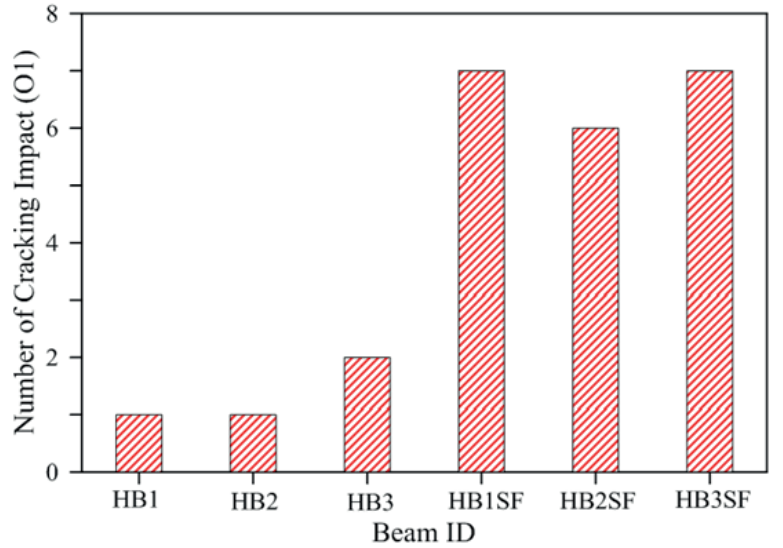

(a)

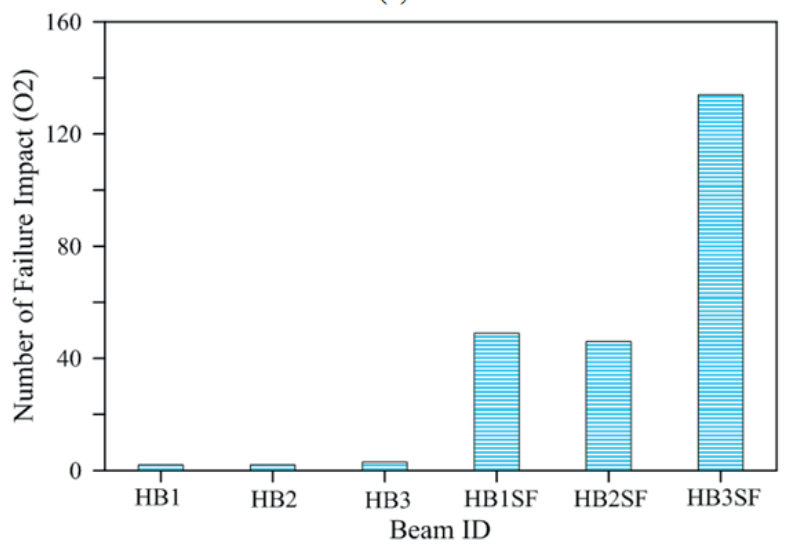

(b)

Fig. 10 Number of impact blows of the six hammerhead beams at cracking and failure stages

the impact resistance of the optimized beams after crack formation. This increase is attributed to the superior bridging activity of steel fibers across the cracks, whereas cracks tend to widen and propagate under the effect of the repeated impacts, the fibers bridge the crack faces sustaining the vast of the tensile stresses across and along these cracks. As tensile stresses increase, either the bond between fibers and concrete breaks gradually until bond pull-out failure or the fiber ruptures when tensile stress exceeds its tensile strength [57]. The orientation of fibers and dispersal are two factors that can have a profound effect on the impact resistance of fibrous hammerhead concrete beams, consequently influenced by mixing method, casting technique, and beam/ specimen dimensions [58-62]. The impact energy results are shown in Fig. 11 confirm the abovementioned results. The cracking impact energy of beams HB1, HB2, HB3, HB1SF, HB2SF, and HB3SF were approximately 41, 41, 81, 285,244 , and $285 \mathrm{~J}$, respectively, while their corresponding energies at failure were 81, 81, 122, 1994, 1872 and $5453 \mathrm{~J}$, respectively. The above results also lead to the conclusion that the beam HB3 exhibited the highest impact resistance both for plain and fibrous cases and both at cracking and failure stages, which confirm the conclusion obtained from the static test that beam HB3 was the best choice among the three optimized beams.

Fig. 12 gives a clearer picture of the evolution of impact resistance after crack formation for the six hammerhead beams, in which the quantity $(\mathrm{O} 2-\mathrm{O} 1)$ is normalized to O1. This value quantitatively evaluates the impact resistance of each of the tested beams along the post-cracking region compared to that at the cracking stage, making it a possible measurement of impact ductility. It is evident in Fig. 12 that the $(\mathrm{O} 2-\mathrm{O} 1)$ ratio was equal or less than 1.0 for plain beams, which reveals the brittleness of these beams after crack formation, while those of fibrous beams were in general not less than 6.0, which reflects their ductile behavior after cracking. Fig. 12 shows that based on these measurements, the fibrous copy of the optimized beam HB3 (HB3SF) exhibited the highest ductility among the six beams with an (O2-O1) ratio of approximately 18 . These results confirm the HB3 beam again with $1.5 \%$

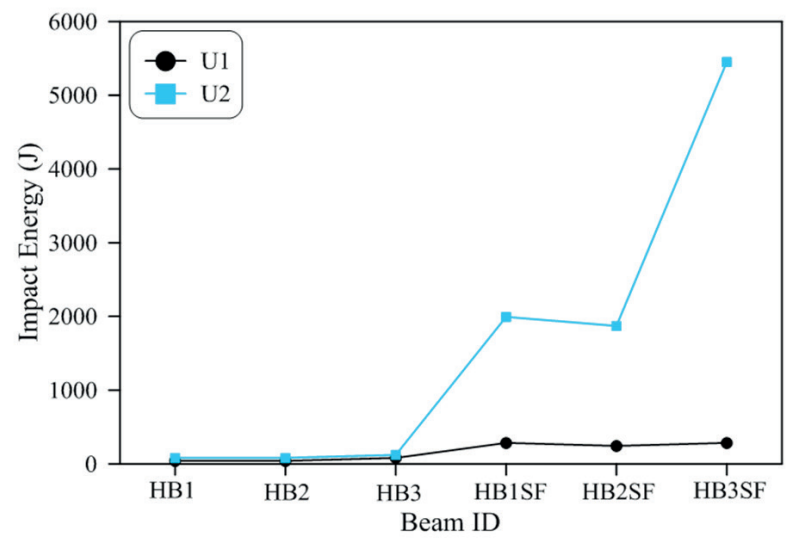

Fig. 11 Impact Energy of the six hammerhead beams at cracking and failure stages

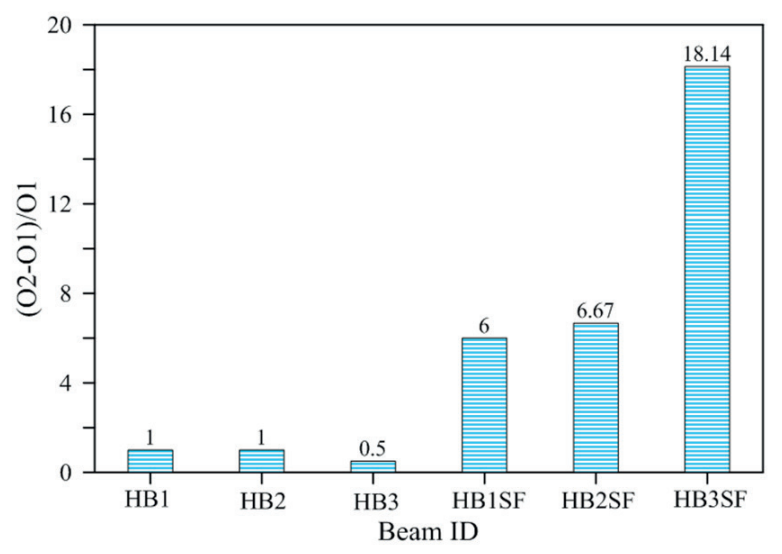

Fig. 12 Difference of failure and cracking numbers of impact for the six hammerhead beams 


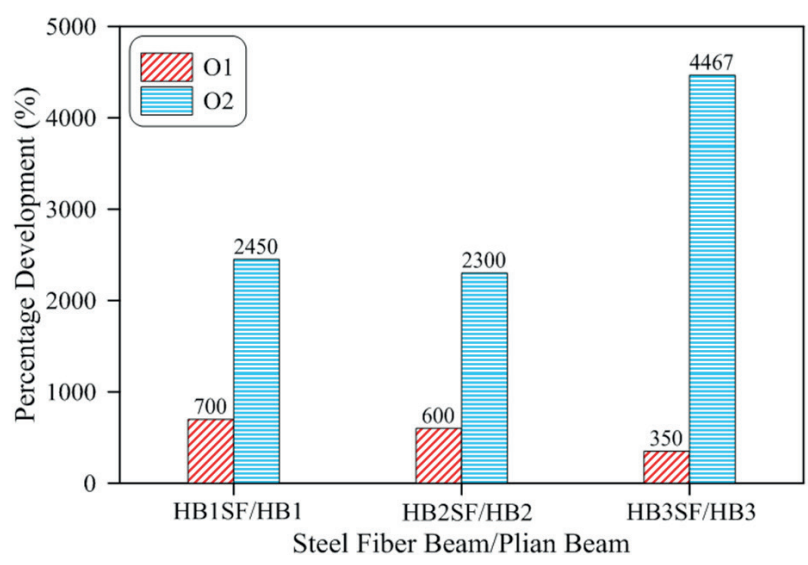

Fig. 13 Percentage development in impact resistance at cracking and failure due to steel fiber

of steel fiber is the best alternative among the three optimized beams on the bases of strength, impact energy, and impact ductility.

Fig. 13 visualizes the additional impact resistance gained by the inclusion of steel fiber to each of the three optimized beams HB1, HB2, and HB3 both at cracking and failure stages. This effect is presented in terms of the ratio of the impact number of blows of the fibrous beam to its corresponding plain beam, both for $\mathrm{O} 1$ and $\mathrm{O} 2$. As shown in Fig. 13, the percentage developments in the cracking stage were from 350 to $700 \%$, while the real effect of steel fiber becomes obvious at the failure stage where percentage developments above $2400 \%$ were recorded. These results were explained above and attributed to the functionality of steel fiber in impact resistance. This fiber bridging mechanism plays a vital role in augmenting the impact strength after crack initiation by engrossing and dispersing the impact energy via the deboning of fibers, slips off, and pulls out together along with postponing crack growth $[63,64]$. The Fig. 13 also reinforces the conclusion that HB3 optimized beam with steel fiber (HB3SF) is the recommended one among

The investigated beams, where the ratio HB3SF/HB3 is the highest among the three-beam with $4467 \%$.

\subsection{Cracking patterns of hammerhead pier beams under impact load}

Fig. 14 illustrates the formed cracking patterns on hammerhead pier beams, which were examined under the falling weight collision test experimentally and numerically. In the numerical simulation, the initial and ultimate cracking pattern has been described based on the factor safety. Two distinct types of cracking patterns were observed in hammerhead pier beams. For the HB1 and HB2 beams,

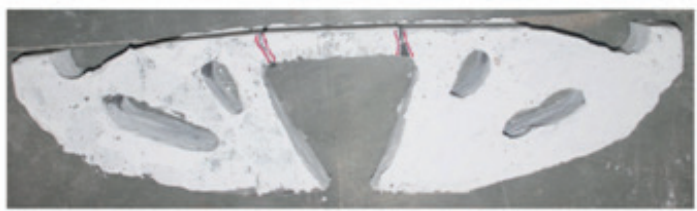

(a) HB1

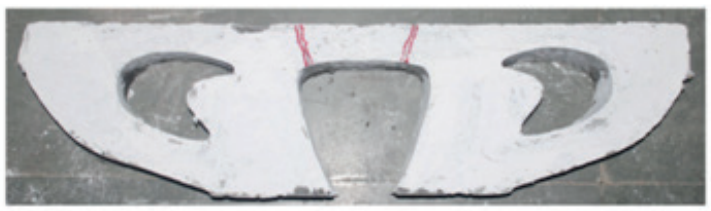

(b) HB2

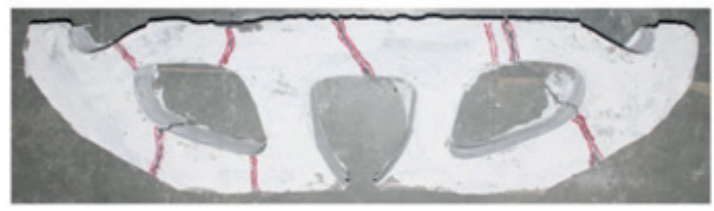

(c) HB3

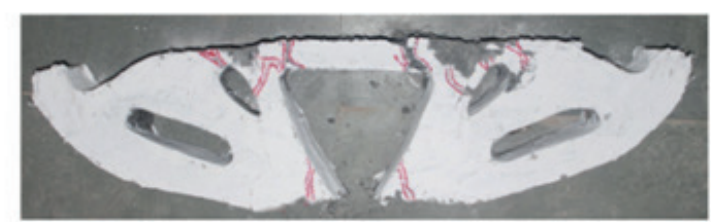

(d) HB1SF

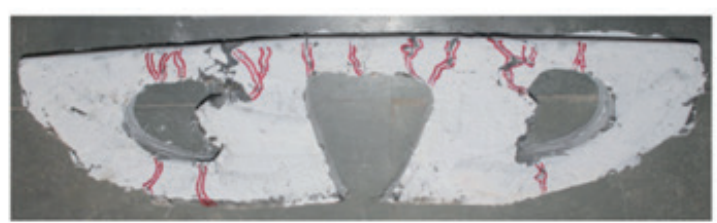

(e) HB 2SF

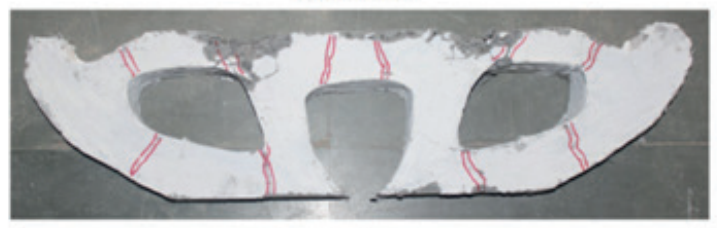

(f) HB3SF

Fig. 14 Experimental cracking patterns of the beams tested under repeated impact

when the crack initiation happens during the first impact, the beam came tumbling down instantly into two fragments during the second impact (Fig. 14). The crack initiation and ultimate crack occurred in between the two-point of applied impact load and exhibited noticeably brittle failure behavior. Contrary to the HB3 beam, crack initiation and ultimate crack occurred in many places at the top and bottom chord of beams and were tumbling down instantly into many fragments. This is attributed to the effectiveness of a non-fibrous hammerhead pier beam designed with topology optimization which can exhibit superior cracking performance associated with HB1 and HB2 beams. 
Fig. 14(d-f) depicts the effect of the addition of steel fibers in hammerhead pier beams (HB1SF-HB3SF) that significantly transformed the cracking configuration from a huge secluded crack to multifarious small cracks, increased the number of cracks considerably while lessening their widths. Consequently, the observed cracking pattern in fibrous hammerhead pier beams were innumerable fine cracks, unlike the solitary macro crack existing in non-fibrous hammerhead pier beams. The formation of small multifarious cracks in the tension zone of the beam is due to the fiber bridging action offered by the hooked end steel fibers which enabled the absorption of more collision energy and prohibited the sudden or rapid failure of beams $[65,66]$. It displays the well-dispersed tensile stress and pointedly ductile failure mode observed after impact loading [67].

\subsection{The failure mechanism of hammerhead pier beams}

The destruction spotted after falling mass testing of fibrous hammerhead pier beams are contact destruction, fiber rupturing, matrix failure, and fiber delaminating. The several influences of impact in every single step are depicted in Fig. 15. This encompasses localized contact destruction owing to the application of falling mass, inner deboning of beams because the transverse shear stress/strain, breakdown of matrix/fiber triggered due to compressive bending on impact plane. Eventually, transferring the fiber deboning action to the neighboring layers is because of tensile bending that occurs in the tension zones. The large quantities of initial kinetic energy are transmitted to the fibers, even though there is the development of an initial crack in the beams [5]. This implies that the fibers can limit crack proliferation and energy-dissipation to the remaining region of concrete. Henceforth, an important juncture in failure mechanism is which forms negative implications in impact properties and it is extraordinarily difficult to notice this in operation.

\section{Conclusions}

Aiming at the investigation of the impact behavior of optimized hammerhead pier beams, FE-based topology optimization was conducted using three different mesh sizes. Based on this study, three beams with optimized geometries that save more than $50 \%$ of the beam's weight were obtained. Experimental beams that are identical in geometry and configuration were cast, tested under static bending, and compared with similar FE models. More six beams having the same three configurations were then cast with and without steel fibers and tested under repeated impact

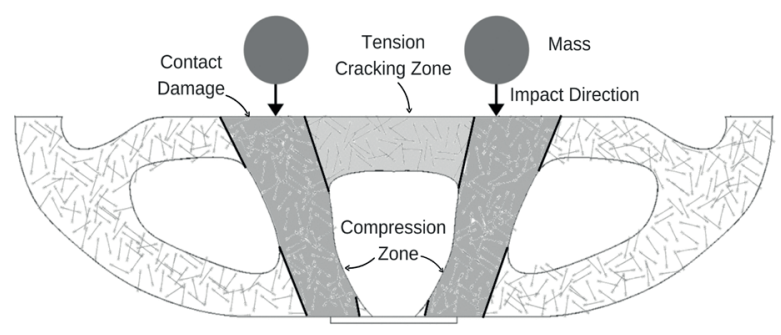

Fig. 15 Failure mechanism of hammerhead pier beam under falling mass impact

to evaluate the impact resistance of the optimized beams. The main conclusions from the FE and experimental studies conducted in this research are summarized as follows:

1. The emphasis of this line of research has been on the design of the concrete structure with better outcomes in the elastic range. The two used design outlines; first targeting at producing a rigid structural design with a specific quantity of material and second targeting at producing light in weight structure with a constrained stress field. By comparing the experimental exploits of the diverse design outlines recommend that the target considered normally will have little awareness of the local concrete composites. Many performance properties are not being able to control the design and have been spotted to differ greatly between the tested beams in the same design case. Though, as a majority of structural components have a multitude of performance supplies there is an essentiality for adding a multitude performance in the design preparation.

2. Based on three different mesh sizes of $7 \mathrm{~mm}, 10 \mathrm{~mm}$, and adaptive mesh, three optimized hammerhead pier beam configurations were reached and termed as HB1, HB2, and HB3, respectively. The volume reduction of the three beams was higher than $50 \%$ of the original volume of the rectangular beam. The findings from the Autodesk fusion 360 static FE analyses were examined and compared with experimental outcomes for the three optimized beams under the static bending test. The comparisons showed that the FE and experimental results were reasonably close in terms of failure loads and final deflections. The differences between the FE and experimental failure loads of the three beams HB1, HB2, and HB3 were in the range of 1.2 and $2.0 \mathrm{kN}$, while the percentage errors in the total deflections were in the range of 6.3 and $11.9 \%$.

3. Based on the experimental static bending test, the comparison among the three optimized beams HB1, HB2, and HB3 revealed that the third beam resulted 
from the adaptive mesh-topology optimization exhibited the best flexural performance among the three beams. The retained flexural strength in terms of failure load of the beam HB3 was higher than the beams HB1 and HB2 by 81 and $347 \%$, respectively. The beam HB3 also retained significantly higher deflection at failure than the other two beams.

4. The test results of repeated impact showed that among the originally optimized plain beams HB1, HB2, and HB3, HB3, the beam HB3 also exhibited the highest impact resistance. Although all of the three beams exhibited very low impact strength both at cracking and failure stages. The beams were cracked after one or two blows of $4.5 \mathrm{~kg}$ balls than fall from an altitude of $457 \mathrm{~mm}$, while one more impact blow led to the failure (crack propagation) of the three beams. This reflects the brittle performance of the plain beams under impact loads.

5. Adding a $1.5 \%$ volume content of hooked-end steel fibers to the same concrete mixture led to dramatic augmentation in the impact resistance of the three optimized beams. The fibrous beams HB1SF, HB2SF, and HB3SF, which are copies (but with steel fiber) of the optimized beams HB1, HB2, and HB3, respectively, retained much higher numbers of impact blow at both cracking and failure stages compared to their plain correspondences. The percentage increase in impact resistance due to fiber inclusion was between 350 and $700 \%$ at cracking, while it was in general higher than $2300 \%$ at the failure stage. Where the beams HB1SF, HB2SF, and HB3SF retained 49, 46 and 134 impact blows at failure with impact energies of 1994, 1872, and $5453 \mathrm{~J}$, respectively. On the other hand, the impact number of blows at the failure of plain beams HB1, HB2, and HB3 were only 2, 2, and 3, respectively, with impact energies of 285,244 , and 285 , respectively.

6 . The measurement of the ratio of post-cracking residual impact strength $(\mathrm{O} 2-\mathrm{O} 1)$ to the impact strength at cracking $\mathrm{O} 1$ was termed as an impact ductility ratio. This ratio revealed the superiority of fibrous beams which exhibited ductile behavior over plain beams that exhibited brittle behavior. The impact ductility ratios of the fibrous beams were in general higher than 6.0 for all of the three-beam, while that of the plain beams was limited with a maximum of only 1.0. The multi-cracking failure behavior of the fibrous beams was another evidence of the ductile performance of these beams.
7. Two distinct types of cracking patterns were observed in hammerhead pier beams. For non-fibrous beams (HB1-HB3), when the crack initiation happens during the first/second impact, the beams were tumbling down instantly into two or more fragments after the multiple impacts which exhibited a sudden brittle failure which is not desirable for concrete structures. On the other hand, fibrous beams (HB1SF-HB3SF) significantly transformed the cracking configuration from a huge secluded crack to small multifarious cracks; increased the number of cracks while lessening their widths. The ductile mode of cracking pattern was observed in fibrous concrete beams which demonstrate the salutary impact of fiber presence in concrete.

8. Comparisons of the impact performances among the three plain beams HB1, HB2, and HB3, and among the three fibrous beams HB1SF, HB2SF, and HB3SF reveal the superiority of the adaptive mesh-based optimized beam (HB3 and HB3SF) in impact resistance in terms of absorbed impact energy and impact ductility. The failure number of impacts and its corresponding absorbed energy of the beam HB1SF were higher than those of beams HB1SF and HB2SF by 173 and $191 \%$, respectively. Similarly, the ductility impact ratio of the beam HB1SF was 18.1, while those of beams HB1SF and HB2SF were 6.0 and 6.7, respectively, with a percentage increase of 170 to $200 \%$.

The Disadvantage of the proposed topology optimized structure is complicated to prepare framework due to complex shapes. Additive manufacturing will reduce post-processing, and also it does not require any framework. However, in the meantime, concrete $3 \mathrm{D}$ printing is at the starting stage, and it needs to evolve with the capacity of printing structural elements. In future research makes it possible to create the structural elements with reinforcement by using 3D Concrete printing.

\section{List of acronyms}

$[\mathrm{K}]$

[M]

3D

ACI

FE

FEM

$\mathrm{g}$

$\mathrm{H}$

HB
Stiffness matrix

Mass matrix

Three dimensions

American Concrete Institute

Finite Element

Finite Element method

Acceleration due to gravity

Denotes the height of free fall

Hammerhead pier beam 


$\begin{array}{ll}\text { LVDT } & \text { Linear Variable Differential Transformer } \\ \mathrm{m} & \text { Mass of dropping a steel ball } \\ \mathrm{MMA} & \text { Moving Method Asymptotes } \\ \mathrm{N} & \text { Number of replicated impacts } \\ \mathrm{O} 1 & \text { Impact strength at cracking } \\ \mathrm{O} 2 & \text { Impact strength at failure } \\ \text { OCM } & \text { Optimality Criteria Technique } \\ \text { RCC } & \text { Reinforced cement concrete }\end{array}$

\section{References}

[1] Bendsoe, M. P., Sigmund, O. "Topology Optimization Theory, Methods and Applications", Springer-Verlag, Berlin, Heidelberg, Germany, 2003.

https://doi.org/10.1007/978-3-662-05086-6

[2] Briseghella, B., Fenu, L., Feng, Y., Lan, C., Mazzarolo, E., Zordan, T. "Optimization Indexes to Identify the Optimal Design Solution of Shell-Supported Bridges", Journal of Bridge Engineering, 21(3), Article number: 04015067, 2016.

https://doi.org/10.1061/(ASCE)BE.1943-5592.0000838

[3] Diehl, M., Glineur, F., Jarlebring, L., Michiels, W. "Recent Advances in Optimization and its Applications in Engineering", SpringerVerlag, Berlin, Heidelberg, Germany, 2010. https://doi.org/10.1007/978-3-642-12598-0

[4] Liew, A., López López, D., Van Mele, T., Block, P. "Design, fabrication and testing of a prototype, thin-vaulted, unreinforced concrete floor", Engineering Structures, 137, pp. 323-335, 2017.

https://doi.org/10.1016/j.engstruct.2017.01.075

[5] Kumar, P. "Optimal force transmission in reinforced concrete deep beams", Computers \& Structures, 8(2), pp. 223-229, 1978.

https://doi.org/10.1016/0045-7949(78)90026-3

[6] Biondini, F., Bontempi, F., Malerba, P. G. "Optimal strut-andtie models in reinforced concrete structures", Computer Assisted Mechanics and Engineering Sciences, 6, pp. 280-293, 1999.

[7] Bruggi, M. "Generating strut-and-tie patterns for reinforced concrete structures using topology optimization", Computers \& Structures, 87(23-24), pp. 1483-1495, 2009.

https://doi.org/10.1016/j.compstruc.2009.06.003

[8] Bruggi, M. "On the Automatic Generation of Strut and Tie Patterns under Multiple Load Cases with Application to the Aseismic Design of Concrete Structures", Advances in Structural Engineering, 13(6), pp. 1167-1181, 2010.

https://doi.org/10.1260/1369-4332.13.6.1167

[9] Victoria, M., Querin, O. M., Martí, P. "Generation of strut-andtie models by topology design using different material properties in tension and compression", Structural and Multidisciplinary Optimization, 44, pp. 247-258, 2011.

https://doi.org/10.1007/s00158-011-0633-z

[10] Gaynor, A. T., Guest, J. K., Moen, C. D. "Reinforced Concrete Force Visualization and Design Using Bilinear Truss-Continuum Topology Optimization", Journal of Structural Engineering, 139(4), pp. 607-618, 2012.

https://doi.org/10.1061/(asce)st.1943-541x.0000692

$\begin{array}{ll}\text { SF } & \text { Steel fiber } \\ \text { SIMP } & \text { Solid isotropic material penalization } \\ \text { SP } & \text { Superplasticizer } \\ \mathrm{U} & \text { Collision energy } \\ \mathrm{U} 1 & \text { Impact energies at cracking } \\ \mathrm{U} 2 & \text { Impact energies at failure } \\ X_{e} & \text { Density function } \\ \sigma_{1}, \sigma_{2} & \text { Principal stress plane }\end{array}$

[11] Yang, Y., Moen, C. D., Guest, J. K. "Three-Dimensional Force Flow Paths and Reinforcement Design in Concrete via Stress-Dependent Truss-Continuum Topology Optimization", Journal of Engineering Mechanics, 141(1), Article number: 04014106, 2014. https://doi.org/10.1061/(asce)em.1943-7889.0000819

[12] Ali, M. A., White, R. N. "Automatic Generation of Truss Model for Optimal Design of Reinforced Concrete Structures", ACI Structural Journal, 98(4), pp. 431-442, 2001. https://doi.org/10.14359/10286

[13] Bogomolny, M., Amir, O. "Conceptual design of reinforced concrete structures using topology optimization with elastoplastic material modeling", International Journal for Numerical Methods in Engineering, 90(13), pp. 1578-1597, 2012. https://doi.org/10.1002/nme.4253

[14] Shaw, D., Miles, J., Gray, A. "Determining the structural layout of orthogonal framed buildings", Computers \& Structures, 86(19-20), pp. 1856-1864, 2008.

https://doi.org/10.1016/j.compstruc.2008.04.009

[15] Nimtawat, A., Nanakorn, P. "Automated layout design of beam-slab floors using a genetic algorithm", Computers \& Structures, 87(2122), pp. 1308-1330, 2009.

https://doi.org/10.1016/j.compstruc.2009.06.007

[16] Nimtawat, A., Nanakorn, P. "A genetic algorithm for beam-slab layout design of rectilinear floors", Engineering Structures, 32(11), pp. 3488-3500, 2010. https://doi.org/10.1016/j.engstruct.2010.07.018

[17] Briseghella, B., Fenu, L., Feng, Y., Mazzarolo, E., Zordan, T. "Topology Optimization of Bridges Supported by a Concrete Shell", Structural Engineering International, 23(3), pp. 285-294, 2013. https://doi.org/10.2749/101686613X13363929988214

[18] Kato, J., Ramm, E. "Optimization of fiber geometry for fibber reinforced composites considering damage", Finite Elements in Analysis and Design, 46(5), pp. 401-415, 2010. https://doi.org/10.1016/j.finel.2010.01.001

[19] Amir, O., Sigmund, O. "Reinforcement layout design for concrete structures based on continuum damage and truss topology optimization", Structural and Multidisciplinary Optimization, 47, pp. 157174, 2013.

https://oi.org/10.1007/s00158-012-0817-1

[20] Bruggi, M., Taliercio, A. "Topology optimization of the fiber-reinforcement retrofitting existing structures", International Journal of Solids and Structures, 50(1), pp. 121-136, 2013. https://doi.org/10.1016/j.ijsolstr.2012.09.009 
[21] Amir, O. "A topology optimization procedure for reinforced concrete structures", Computers \& Structures, 114-115, pp. 46-58, 2013. https://doi.org/10.1016/j.compstruc.2012.10.011

[22] Amir, O., Shakour, E. "Simultaneous shape and topology optimization of prestressed concrete beams", Structural and Multidisciplinary Optimization, 57, pp.1831-1843, 2018.

https://doi.org/10.1007/s00158-017-1855-5

[23] Søndergaard, A., Dombernowsky, P. "Design, Analysis and Realization Of Topology Optimized Concrete Structures", International Association for Shell and Spatial Structures, 53(4), pp. 209-216, 2012.

[24] Oviedo, R., Gutiérrez, S., Santa María, H. "Experimental evaluation of optimized strut-and-tie models for a dapped beam", Structural Concrete, 17(3), pp. 469-480, 2016.

https://doi.org/10.1002/suco.201500037

[25] Song, D., Tan, Q., Zhan, H., Liu, F., Jiang, Z. "Experimental investigation on the cellular steel-tube-confined concrete targets against projectile impact", International Journal of Impact Engineering, 131, pp. 94-110, 2019.

https://doi.org/10.1016/j.ijimpeng.2019.05.004

[26] Asrani, N. P., Murali, G., Parthiban, K., Surya, K., Prakash, A., Rathika, K., Chandru, U. "A feasibility of enhancing the impact resistance of hybrid fibrous geopolymer composites: Experiments and modelling", Construction and Building Materials, 203, pp. $56-68,2019$.

https://doi.org/10.1016/j.conbuildmat.2019.01.072

[27] Do, T. V., Pham, T. M., Hao, H. "Effects of steel confinement and shear keys on the impact responses of precast concrete segmental columns", Journal of Constructional Steel Research, 158, pp. 331349, 2019.

https://doi.org/10.1016/j.jcsr.2019.04.008

[28] Ismail, M. K., Hassan, A. A. A., Lachemi, M. "Effect of Fibber Type on Impact and Abrasion Resistance of Engineered Cementitious Composite", ACI Materials Journal, 115(6), pp. 957-968, 2018.

[29] Mastali, M., Dalvand, A., Sattarifard, A. R. "The impact resistance and mechanical properties of reinforced self-compacting concrete with recycled glass fibre reinforced polymers", Journal of Cleaner Production, 124, pp. 312-324, 2016. https://doi.org/10.1016/j.jclepro.2016.02.148

[30] Gencel, O., Brostow, W., Datashvili, T., Thedford, M. "Workability and Mechanical Performance of Steel Fiber-Reinforced SelfCompacting Concrete with Fly Ash", Composite Interfaces, 18(2), pp. 169-184, 2011.

https://doi.org/10.1163/092764411X567567

[31] Silva, E. R., Coelho, J. F. J., Bordado, J. C. "Strength improvement of mortar composites reinforced with newly hybrid-blended fibres: Influence of fibres geometry and morphology", Construction and Building Materials, 40, pp. 473-480, 2013. https://doi.org/10.1016/j.conbuildmat.2012.11.017

[32] Abirami, T., Loganaganandan, M., Murali, G., Fediuk, R., Vickhram Sreekrishna, R., Vignesh, T., Januppriya, G., Karthikeyan, K. "Experimental research on impact response of novel steel fibrous concretes under falling mass impact", Construction and Building Materials, 222, pp. 447-457, 2019.

https://doi.org/10.1016/j.conbuildmat.2019.06.175

[33] Ramkumar, V. R., Murali, G., Asrani, N. P., Karthikeyan, K.
"Development of a novel low carbon cementitious two stage layered fibrous concrete with superior impact strength", Journal of Building Engineering, 25, Article number: 100841, 2019.

https://doi.org/10.1016/j.jobe.2019.100841

[34] Al-Hadithi, A. I., Noaman, A. T., Mosleh, W. K. "Mechanical properties and impact behavior of PET fiber reinforced self-compacting concrete (SCC)", Composite Structures, 224, Article number: 111021, 2019.

https://doi.org/10.1016/j.compstruct.2019.111021

[35] Zhang, X., Hao, H. "Improved impact resistant capacity of segmental column with fibre reinforced polymer wrap", International Journal of Impact Engineering, 125, pp. 117-133, 2019.

https://doi.org/10.1016/j.ijimpeng.2018.11.009

[36] Sharafi, P., Hadi, M. N. S., Teh, L. H. "Heuristic Approach for Optimum Cost and Layout Design of 3D Reinforced Concrete Frames", Journal of Structural Engineering, 138(7), pp. 853-863, 2012. https://doi.org/10.1061/(ASCE)ST.1943-541X.0000508

[37] Liu, S., Qiao, H. "Topology optimization of continuum structures with different tensile and compressive properties in bridge layout design", Structural and Multidisciplinary Optimization, 43, pp. 369380, 2011.

https://doi.org/10.1007/s00158-010-0567-x

[38] Sigmund, O., Maute, K. "Topology optimization approaches: A comparative review", Structural and Multidisciplinary Optimization, 48, pp. 1031-1055, 2013.

https://doi.org/10.1007/s00158-013-0978-6

[39] Yang, J. R., Chen, C. J. "Stress-based topology optimization", Structural Optimization, 12, pp. 98-105, 1996. https://doi.org/10.1007/BF01196941

[40] Duysinx, P., Bendsøe, M. P. "Topology Optimization of Continuum Structures with Local Stress Constraints", International Journal for Numerical Methods in Engineering, 43(8), pp. 1453-1478, 1998. https://doi.org/10.1002/(SICI)1097-0207(19981230)43:8<1453:: AID-NME480>3.0.CO;2-2

[41] Picelli, R., Townsend, S., Brampton, C., Norato, J., Kim, H. A. "Stress-based shape and topology optimization with the level set method", Computer Methods in Applied Mechanics and Engineering, 329, pp. 1-23, 2018 . https://doi.org/10.1016/j.cma.2017.09.001

[42] Bruggi, M., Duysinx, P. "Topology optimization for minimum weight with compliance and stress constraints", Structural and Multidisciplinary Optimization, 46, pp. 369-384, 2012. https://doi.org/10.1007/s00158-012-0759-7

[43] Holmberg, E., Torstenfelt, B., Klarbring, A. "Stress constrained topology optimization", Structural and Multidisciplinary Optimization, 48, pp. 33-47, 2013. https://doi.org/10.1007/s00158-012-0880-7

[44] Bruggi, M. "Topology optimization with mixed finite elements on regular grids", Computer Methods in Applied Mechanics and Engineering, 305, pp. 133-153, 2016. https://doi.org/10.1016/j.cma.2016.03.010

[45] Jeong, S. H., Choi, D.-H., Yoon, G. H. "Fatigue and static failure considerations using a topology optimization method", Applied Mathematical Modelling, 39(3-4), pp. 1137-1162, 2015. https://doi.org/10.1016/j.apm.2014.07.020

[46] Le, C., Norato, J., Bruns, T., Ha, C., Tortorelli, D. "Stress-based 
topology optimization for continua", Structural and Multidisciplinary Optimization, 41, pp. 605-620, 2010.

https://doi.org/10.1007/s00158-009-0440-y

[47] Bruggi, M. "A numerical method to generate optimal load paths in plain and reinforced concrete structures", Computers \& Structures, 170, pp. 26-36, 2016.

https://doi.org/10.1016/j.compstruc.2016.03.012

[48] Drucker, D. C., Prager, W. "Soil Mechanics and Plastic Analysis or Limit Design", Quarterly of Applied Mathematics, 10, pp. 157-165, 1943.

https://doi.org/10.1090/qam/48291

[49] Patnaik, S. N., Guptill, J. D., Berke, L. "Merits and limitations of optimality criteria method for structural optimization", International Journal for Numerical Methods in Engineering, 38(18), pp. 30873120, 1995.

https://doi.org/10.1002/nme.1620381806

[50] Lógó, J. "New Type of Optimality Criteria Method in Case of Probabilistic Loading Conditions", Mechanics Based Design of Structures and Machines, 35(2), pp. 147-162, 2007. https://doi.org/10.1080/15397730701243066

[51] Svanberg, K. "The method of moving asymptotes - a new method for structural optimization", International Journal for Numerical Methods in Engineering, 24(2), pp. 359-373, 1987. https://doi.org/10.1002/nme.1620240207

[52] IS "IS:12269-2013 Ordinary Portland Cement, 53 Grade - Specifications", Bureau of Indian Standards, New Delhi, India, 2013.

[53] IS "IS:383-2016 Coarse and Fine Aggregate for Concrete Specification", Bureau of Indian Standards, New Delhi, India, 2016.

[54] ACI "ACI544.2R-89 Measurement of properties of fibber reinforced concrete", ACI Committee, West Conshohocken, PA, USA, 1999.

[55] Jewett, J. L., Carstensen, J. V. "Topology-optimized design, construction and experimental evaluation of concrete beams", Automation in Construction, 102, pp. 59-67, 2019.

https://doi.org/10.1016/j.autcon.2019.02.001

[56] Abid, S. R., Abdul Hussein, M. L., Ali, S. H., Kazem, A. F. "Suggested modified testing techniques to the ACI 544-R repeated drop-weight impact test", Construction and Building Materials, 244, Article number: 118321, 2020.

https://doi.org/10.1016/j.conbuildmat.2020.118321

[57] Abid, S. R., Abdul-Hussein, M. L., Ayoob, N. S., Ali, S. H., Kadhum, A. L. "Repeated drop-weight impact tests on self-compacting concrete reinforced with micro-steel fiber", Heliyon, 6(1), Article number: e03198, 2020.

[58] Song, Q., Yu, R., Shui, Z., Wang, X., Rao, S., Lin, Z., Wang, Z. "Key parameters in optimizing fibres orientation and distribution for Ultra-High Performance Fibre Reinforced Concrete (UHPFRC)", Construction and Building Materials, 188, pp. 17-27, 2018. https://doi.org/10.1016/j.conbuildmat.2018.08.102

[59] Plagué, T., Desmettre, C., Charron, J.-P. "Influence of fiber type and fiber orientation on cracking and permeability of reinforced concrete under tensile loading", Cement and Concrete Research, 94, pp. 59-70, 2017.

https://doi.org/10.1016/j.cemconres.2017.01.004

[60] Alberti, M. G., Enfedaque, A., Gálvez, J. C. "On the prediction of the orientation factor and fibre distribution of steel and macro-synthetic fibres for fibre-reinforced concrete", Cement and Concrete Composites, 77, pp. 29-48, 2017.

https://doi.org/10.1016/j.cemconcomp.2016.11.008

[61] Alberti, M. G., Enfedaque, A., Gálvez, J. C. "A review on the assessment and prediction of the orientation and distribution of fibres for concrete", Composites Part B: Engineering, 151, pp. 274290, 2018 .

https://doi.org/10.1016/j.compositesb.2018.05.040

[62] Eik, M., Papenfuss, C. "Velocity gradients of concrete mass reconstructed based on measured fibre orientations in hardened concrete", Composite Structures, 225, Article number: 111008, 2019. https://doi.org/10.1016/j.compstruct.2019.111008

[63] Kushch, V. I., Shmegera, S. V., Brøndsted, P., Mishnaevsky Jr, L. "Numerical simulation of progressive debonding in fiber reinforced composite under transverse loading", International Journal of Engineering Science, 49(1), pp. 17-29, 2011. https://doi.org/10.1016/j.jiengsci.2010.06.020

[64] Romanowicz, M. "Effect of interfacial debonding on the failure behavior in a fiber-reinforced composite subjected to transverse tension", Computational Materials Science, 47(1), pp. 225-231, 2009. https://doi.org/10.1016/j.commatsci.2009.07.011

[65] Murali, G., Santhi, A. S., Ganesh, G. M. "Empirical Relationship between the Impact Energy and Compressive Strength for Fibber Reinforced Concrete", Journal of Scientific \& Industrial Research, 73, pp. 469-473, 2014.

[66] Murali, G., Santhi, S. A., Ganesh, G. M. "Impact Resistance and Strength Reliability of Fiber-reinforced Concrete in Bending under Drop Weight Impact Load", International Journal of Technology, 5(2), pp. 111-120, 2014. https://doi.org/10.14716/ijtech.v5i2.403

[67] Murali, G., Santhi, S. A., Mohan Ganesh, G. "Effect of Crimped and Hooked End Steel Fibres on the Impact Resistance of Concrete", Journal of Applied Science and Engineering, 17(3), pp. 259-266, 2014.

https://doi.org/10.6180/jase.2014.17.3.06 